\title{
Delayed diagnosis of tuberculosis in persons living with HIV in Eastern Europe: associated factors and effect on mortality-a multicentre prospective cohort study
}

\author{
Christian Kraef 1,2,14*, Adrian Bentzon ${ }^{1}$, Alexander Panteleev ${ }^{3}$, Alena Skrahina ${ }^{4}$, Natalie Bolokadze ${ }^{5}$, \\ Simona Tetradov ${ }^{6}$, Regina Podlasin ${ }^{7}$, Igor Karpov ${ }^{8}$, Elena Borodulina ${ }^{9}$, Elena Denisova ${ }^{10}$, Inga Azina ${ }^{11}$, \\ Jens Lundgren', Isik Somuncu Johansen ${ }^{12}$, Amanda Mocroft ${ }^{1,13}$, Daria Podlekareva ${ }^{1}$ and Ole Kirk ${ }^{1,2,12}$ for the T. \\ B.H. I. V. Study Group
}

\begin{abstract}
Background: Early diagnosis of tuberculosis (TB) is important to reduce transmission, morbidity and mortality in people living with HIV (PLWH).

Methods: PLWH with a diagnosis of TB were enrolled from HIV and TB clinics in Eastern Europe and followed until 24 months. Delayed diagnosis was defined as duration of TB symptoms (cough, weight-loss or fever) for $\geq 1$ month before TB diagnosis. Risk factors for delayed TB diagnosis were assessed using multivariable logistic regression. The effect of delayed diagnosis on mortality was assessed using Kaplan-Meier estimates and Cox models.

Findings: $480 / 740$ patients $(64.9 \% ; 95 \% \mathrm{Cl} 61.3-68.3 \%)$ experienced a delayed diagnosis. Age $\geq 50$ years (vs. $<50$ years, $a O R=2.51 ; 1.18-5.32 ; p=0.016)$, injecting drug use (IDU) (vs. non-IDU $a O R=1.66 ; 1.21-2.29 ; p=0.002$ ), being ART naïve $(a O R=1.77 ; 1.24-2.54 ; p=0.002)$, disseminated TB (vs. pulmonary $\mathrm{TB}, \mathrm{aOR}=1.56,1.10-2.19$, $p=0.012$ ), and presenting with weight loss (vs. no weight loss, $a O R=1.63 ; 1.18-2.24 ; p=0.003$ ) were associated with delayed diagnosis. PLWH with a delayed diagnosis were at $36 \%$ increased risk of death (hazard ratio $=1.36 ; 1.04-1.77$; $\mathrm{p}=0.023$, adjusted hazard ratio $1.27 ; 0.95-1.70 ; \mathrm{p}=0.103$ ).

Conclusion: Nearly two thirds of PLWH with TB in Eastern Europe had a delayed TB diagnosis, in particular those of older age, people who inject drugs, ART naïve, with disseminated disease, and presenting with weight loss. Patients with delayed TB diagnosis were subsequently at higher risk of death in unadjusted analysis. There is a need for optimisation of the current TB diagnostic cascade and HIV care in PLWH in Eastern Europe.
\end{abstract}

\footnotetext{
*Correspondence: christiankraef@gmail.com

${ }^{1}$ CHIP (Centre of Excellence for Health, Immunity and Infections), Rigshospitalet, University of Copenhagen, Copenhagen, Denmark Full list of author information is available at the end of the article
}

\section{Introduction}

Globally, about 10 million people were diagnosed with tuberculosis (TB) in 2019 [1]. Among those, 8.2\% were people living with the human immunodeficiency virus (PLWH) [1]. Among PLWH, TB is the most frequent coinfection, cause for hospitalization and cause of death, responsible for about 208,000 AIDS-related deaths worldwide in 2019 [1, 2]. One major challenge to improve 
survival for TB patients is to ensure timely diagnosis of TB [3]. In patients mono-infected with TB a recent systematic review of delay in diagnosis of pulmonary TB in low- and middle income countries found that $42 \%$ of TB patients had a delay between symptom onset and TB diagnosis of at least a month [4]. A systematic review of post-mortem studies from Africa, Asia and the Americas found TB as the cause of death in $37.2 \%$ of PLWH, of which $45.8 \%$ remained undiagnosed at the point of death [3]. Delayed diagnosis of TB has repeatedly been shown to lead to more severe disease presentation, and increases morbidity and mortality significantly [5-11]. Furthermore, delayed TB diagnosis increases the risk for TB community transmission $[6,12]$.

In consequence, one component of the World Health Organization's End TB strategy to reduce TB deaths by $75 \%$ and TB incidence by $50 \%$ in the general population by the year 2025 is ensuring early diagnosis of TB [13]. To this end, the strategy identifies amongst others the mapping of high-risk groups and the implementation of carefully planned systematic screening for active disease among identified high-risk groups as important facilitators of early diagnosis [13]. One high-risk group are $\mathrm{PLWH}$, in whom the effect of delayed diagnosis on morbidity and mortality is even more distinct compared to those mono-infected with TB [14-16].

HIV/TB-coinfections continue to be a major challenge in many Eastern European countries [17]. In a large clinical cohort of patients with HIV/TB across Eastern Europe, 1-year mortality was $27 \%$, with the majority of those deaths (79\%) directly attributable to TB [17]. That is a risk of death nearly four-times higher than that in PLWH with TB from western Europe and Latin America [17].

However, to the best of our knowledge, the contribution of delayed TB diagnosis to morbidity and mortality and its associated factors in PLWH have not been investigated in an Eastern European setting. The objective of this study is to describe the prevalence of delayed diagnosis, analyze factors associated with delayed diagnosis and to quantify the effect of delayed diagnosis on survival in PLWH.

\section{Methods}

\section{Study design, population and sample}

The data for this analysis were drawn form an international prospective observational cohort study (TB:HIV study). Details of the study have previously been published [17]. Study protocols and forms are available at www.chip.dk. Only patients included at Eastern European study sites were included in the current analysis. The TB:HIV study enrolled consecutive HIV-patients with TB diagnosis aged 16 years or older from 21 HIV and TB clinics in nine Eastern European countries (Belarus, Estonia, Georgia, Latvia, Lithuania, Poland, Romania, Russia and Ukraine) between Jan 1, 2011 and Dec 31, 2013 [17]. All methods were carried out in accordance with relevant guidelines and regulations. All participating clinics obtained ethical approval in accordance with local rules and legislations. A list of IEC/IRB from each participating center is provided in Appendix. Informed consent was obtained from all participants. The study was performed in accordance with the STROBE guidelines for observational studies [18].

\section{Variables, inclusion and exclusion criteria}

Explanatory variables include demography data, previous TB-disease, type of TB diagnosis, clinical presentation of current TB, HIV characteristics including CD4 cell counts and HIV-RNA measurements, antiretroviral therapy (ART) history and AIDS defining diagnoses. Variables with missing information on treatment with cotrimoxazole, chest $\mathrm{x}$-ray, $\mathrm{HBsAg}$, Anti-HCV and TB risk factors (alcohol, previous $\mathrm{TB}$, imprisonment) were assumed as absent. Those with missing information on CD4 count were included as a separate category. For drug-susceptibility testing and determination of MDR$\mathrm{TB}$, if some information on drug-susceptibility was present, but missing for a specific drug M. tuberculosis was assumed to be susceptible to that specific drug, as done previously [19].

To evaluate the delayed diagnosis, we used the variable "symptom duration" prior to diagnosis that was captured as a categorical variable $(<1$ month, $1-3$ months and $>3$ months) in the original enrollment form by the enrolling health care worker based on self-reporting by the PLWH. For the purpose of this study, we merged the categories to create a binary variable ( $\geq 1$ months versus $<1$ months).

\section{Box 1. Study definitions}

\begin{tabular}{|c|c|c|}
\hline Region & Eastern Europe & $\begin{array}{l}\text { Belarus, Estonia, Georgia, } \\
\text { Latvia, Lithuania, Poland, } \\
\text { Romania, Ukraine, Russia }\end{array}$ \\
\hline Delayed diagnosis & & $\begin{array}{l}\text { Delayed diagnosis was } \\
\text { defined as duration of TB } \\
\text { symptoms (cough, weight- } \\
\text { loss or fever) for } \geq 1 \text { month } \\
\text { before TB diagnosis }\end{array}$ \\
\hline TB diagnosis & Definite & $\begin{array}{l}\text { Positive culture or PCR } \\
\text { (Xpert) for Mtb (in sputum } \\
\text { smear or other specimen) }\end{array}$ \\
\hline
\end{tabular}




\begin{tabular}{|c|c|c|}
\hline & Probable & $\begin{array}{l}\text { Acid fast bacilli or } \\
\text { granulomatous inflamma- } \\
\text { tion in sputum smear or } \\
\text { tissue biopsy and other } \\
\text { specimens (e.g., CSF, Pleural } \\
\text { fluid) }\end{array}$ \\
\hline & Presumptive & $\begin{array}{l}\text { A patient who presents } \\
\text { with symptoms or signs } \\
\text { suggestive of TB where TB } \\
\text { treatment is initiated and } \\
\text { not subsequently stopped } \\
\text { because the TB diagnosis } \\
\text { was ruled out }\end{array}$ \\
\hline \multirow[t]{3}{*}{ TB location } & Pulmonary & $\begin{array}{l}\text { TB localised to the lungs, } \\
\text { larynx, or tracheobronchial } \\
\text { tree }\end{array}$ \\
\hline & Extrapulmonary & $\begin{array}{l}\text { just one extra-pulmonary } \\
\text { site was identified }\end{array}$ \\
\hline & Disseminated & $\begin{array}{l}\text { Either of the following: } \\
\text { (i) TB documented in at } \\
\text { least two organ systems } \\
\text { (one of which could be } \\
\text { lungs) } \\
\text { (ii) miliary TB, or } \\
\text { (iii) isolation of Mtb from } \\
\text { blood or bone marrow }\end{array}$ \\
\hline TB drug resistance & MDR & $\begin{array}{l}\text { Mtb resistant to both } \\
\text { rifamycin and isoniazid }\end{array}$ \\
\hline AIDS & & $\begin{array}{l}\text { Clinical AIDS criteria (ref: } \\
1993 \text { Revised Classification } \\
\text { System for HIV Infection } \\
\text { and Expanded Surveillance } \\
\text { Case Definition for AIDS } \\
\text { Among Adolescents and } \\
\text { Adults) }\end{array}$ \\
\hline
\end{tabular}

\section{Data analysis}

Descriptive statistics were used to present data as proportions, medians and interquartile ranges. The Chisquared and Fisher's exact test were used to compare categorical variables between groups, while the KruskalWallis test was used to compare continuous variables.

To identify risk factors for delayed diagnosis we first conducted a bivariate analysis of potential risk factors. Those with a $\mathrm{p} \leq 0.10$ were included in the multivariable logistic regression model.

For the survival analysis baseline was defined as the date of TB treatment initiation. All follow-up was censored at 24 months. Overall survival comparing the group with delayed and non-delayed diagnosis was assessed using the Kaplan-Meier (KM) method and the log-rank test. We used Cox proportional hazards regression models to estimate hazard ratios (HRs) and 95\% confidence intervals (CIs) of the effect of delayed diagnosis on mortality. Variables with a p-value $\leq 0.10$ were included in the multivariate model to assess the hazard ratio (HR) and the Cox-model was stratified by the clinical center. Based on the Kaplan-Maier survival analysis, we decided to stratify the Cox-regression model at 2 months follow-up time (0-2 months and 2-24 months). The proportional hazard assumption was tested based on Schoenfeld residuals. Stata IC 15.1 was used for statistical analysis.

\section{Results}

In the TB:HIV cohort 825 PLWH from Eastern Europe were eligible for the analysis, of those 85 (10.3\%) were excluded because of missing data on symptom duration.

A total of 740 patients from Eastern Europe were included in the current analysis. The analysis included $260(35.1 \%)$ patients with a delay of less than 1 month and $480(64.9 \%)$ patients with a delay of at least 1 month, $380(51.4 \%)$ had a delay of 1-3 months, and 100 (13.5\%) of $>3$ months.

\section{Factors associated with delayed diagnosis}

Baseline characteristics of the TB:HIV patients in Eastern Europe stratified by delayed diagnosis, and factors associated with delayed diagnosis are presented in Table 1 . In the multivariable analysis age $\geq 50$ years (vs. $<50$ years, aOR $2.51,95 \% \mathrm{CI} 1.18-5.32, \mathrm{p}=0.016$ ), Injecting Drug Use (IDU) (vs. non-IDU aOR 1.66, 95\% CI 1.21-2.29, $\mathrm{p}=0.002$ ), being ART treatment naïve at TB diagnosis (vs. any ART before TB diagnosis, aOR 1.77, 95\% CI 1.24-2.54, $\mathrm{p}=0.002$ ), disseminated TB (vs. pulmonary TB, aOR $1.56,95 \%$ CI $1.10-2.19, \mathrm{p}=0.012$ ), and weight loss (vs. no weight loss, aOR 1.63, 95\% CI 1.18$2.24, \mathrm{p}=0.003)$ were associated with delayed diagnosis ( $\geq 1$ month). Conversely, a previous TB diagnosis (vs. never diagnosed with TB, aOR $0.60,95 \%$ CI $0.38-0.95$, $\mathrm{p}=0.029$ ) was associated with earlier diagnosis.

In an analysis of the organ systems affected, i.e. organs where TB was identified during diagnostic work-up (non-exclusive/several sites possible in the same patient) genitourinary (OR 3.64; 95\% CI 1.39-9.52; $\mathrm{p}=0.006)$ and lymphatic TB (OR 2.28; 95\% CI 1.65-3.17; $\mathrm{p}=0.001$ ) were associated with delayed diagnosis, whereas pulmonary TB was not (OR 1.17; 95\% CI 0.74-1.86, $\mathrm{p}=0.504$ ).

\section{Survival analysis}

Survival over 24 months, stratified by delayed diagnosis, is presented in the Kaplan-Maier analysis in Fig. 1. Estimates of all-cause mortality at 24 months were 262 (35.4\%), 80 (30.8\%) in the early diagnosis group and 182 (37.9\%) in the late diagnosis group. In the first 2 months of follow-up, the all-cause mortality rate did not differ between PLWH with and without delayed diagnosis, (100/100-person-years of follow-up (PYFU) (95\% CI 78-127) v. 91/100 PYFY, respectively, log-rank test $\mathrm{p}=0.566$. For the follow-up time from 2 to 24 months allcause mortality rates were $23 / 100$ PYFU (95\% CI 19-28) and 14/100 PYFU (95\% CI 11-19), respectively, log-rank test $\mathrm{p}=0.011$. 
Table 1 Baseline characteristics of the TB:HIV patients in Eastern Europe stratified by delayed diagnosis and factors associated with delayed diagnosis

\begin{tabular}{|c|c|c|c|c|c|c|c|}
\hline & \multirow{3}{*}{$\begin{array}{l}\text { Total } \\
\mathrm{n}=740\end{array}$} & \multicolumn{2}{|c|}{ Delayed diagnosis } & \multirow[t]{3}{*}{ OR $(95 \% \mathrm{Cl})$} & \multirow[t]{3}{*}{ p-value } & \multirow[t]{3}{*}{ Adjusted OR $(95 \% \mathrm{Cl})$} & \multirow[t]{3}{*}{$p$-value } \\
\hline & & \multirow{2}{*}{$\begin{array}{l}<1 \text { month } \\
n=260\end{array}$} & \multirow{2}{*}{$\begin{array}{l}\geq 1 \text { month } \\
n=480\end{array}$} & & & & \\
\hline & & & & & & & \\
\hline \multicolumn{8}{|l|}{ Gender } \\
\hline Male & $563(76.1)$ & $200(76.9)$ & $363(75.6)$ & $0.93(0.65-1.33)$ & 0.69 & & \\
\hline \multicolumn{8}{|l|}{ Age } \\
\hline Age 16-49 & $694(93.8)$ & $250(96.2)$ & $444(92.5)$ & Ref & Ref & Ref & Ref \\
\hline Age $\geq 50$ & $46(6.2)$ & $10(3.8)$ & $36(7.5)$ & $2.62(1.21-5.66)$ & 0.01 & $2.51(1.18-5.32)$ & 0.016 \\
\hline \multicolumn{8}{|l|}{ Exposure group (HIV) } \\
\hline MSM (yes vs no) & $10(1.4)$ & $5(1.9)$ & $5(1.0)$ & $0.54(0.15-1.87)$ & 0.32 & & \\
\hline IDU (yes vs no) & $422(57.0)$ & $132(50.8)$ & $290(60.4)$ & $1.48(1.09-2.00)$ & 0.01 & $1.66(1.21-2.29)$ & 0.002 \\
\hline Heterosexual (yes vs no) & $183(24.7)$ & $72(27.7)$ & $111(23.1)$ & $0.79(0.56-1.11)$ & 0.17 & & \\
\hline Known HIV at TB diagnosis & $668(90.3)$ & $235(90.4)$ & $433(90.2)$ & $0.98(0.59-1.63)$ & 0.94 & & \\
\hline \multicolumn{8}{|l|}{ Treatment history (HIV) } \\
\hline ART naïve at TB diagnosis ${ }^{a}$ & $558(75.4)$ & $176(67.7)$ & $382(79.6)$ & $1.86(1.32-2.63)$ & 0.0001 & $1.77(1.24-2.54)$ & 0.002 \\
\hline ART use at TB diagnosis ${ }^{a}$ & $132(17.8)$ & $59(22.7)$ & $73(15.2)$ & $0.61(0.42-0.9)$ & 0.011 & Omitted $^{d}$ & \\
\hline Cotrimoxazole at TB diagnosis & $273(36.9)$ & $84(32.3)$ & $189(39.4)$ & $1.36(0.99-1.87)$ & 0.057 & $1.25(0.89-1.74)$ & 0.197 \\
\hline \multicolumn{8}{|l|}{ CD4-cell count $/ \mathrm{mm}^{3 \circ}$} \\
\hline $0-199 / \mathrm{mm}^{3}$ & $440(59.5)$ & $151(58.1)$ & $289(70.8)$ & $1.06(0.74-1.52)$ & 0.745 & & \\
\hline$\geq 200$ & $185(25.0)$ & $66(25.4)$ & $119(29.2)$ & Ref & Ref & & \\
\hline Missing CD4 & $115(15.5)$ & $43(37.4)$ & $72(62.6)$ & $0.93(0.57-1.51)$ & 0.764 & & \\
\hline Prior AIDS & $177(23.9)$ & $66(25.4)$ & $111(23.1)$ & $0.88(0.62-1.26)$ & 0.49 & & \\
\hline \multicolumn{8}{|l|}{ Previous TB } \\
\hline Yes vs no & $99(13.4)$ & $46(17.7)$ & $53(11.0)$ & $0.58(0.38-0.89)$ & 0.011 & $0.60(0.38-0.95)$ & 0.029 \\
\hline \multicolumn{8}{|l|}{ TB risk factor } \\
\hline Alcohol abuse (yes vs no) & $186(25.1)$ & $72(27.7)$ & $114(23.8)$ & $0.81(0.58-1.15)$ & 0.24 & & \\
\hline Recent TB in family (yes vs no) & $53(7.2)$ & $17(6.5)$ & $36(7.5)$ & $1.16(0.64-2.11)$ & 0.63 & & \\
\hline Imprisonment within 2 years (yes vs no) & $143(19.3)$ & $47(18.1)$ & $96(20.0)$ & $1.13(0.77-1.67)$ & 0.53 & & \\
\hline \multicolumn{8}{|l|}{ Clinical presentation of TB } \\
\hline Pulmonary (including trachea and larynx) & $239(32.3)$ & $101(38.9)$ & $138(28.8)$ & Ref & Ref & Ref & Ref \\
\hline Extrapulmonary & $54(7.3)$ & $23(8.9)$ & $31(6.5)$ & $0.99(0.54-1.79)$ & 0.964 & $0.83(0.44-1.55)$ & 0.553 \\
\hline Disseminated & $447(60.4)$ & $136(52.3)$ & $311(64.8)$ & $1.67(1.21-2.32)$ & 0.002 & $1.56(1.10-2.19)$ & 0.012 \\
\hline \multicolumn{8}{|l|}{ Localisations TB was found (non-exclusive) } \\
\hline Pulmonary (including trachea and larynx) & $654(88.4)$ & $227(87.3)$ & $427(89.0)$ & $1.17(0.74-1.86)$ & 0.504 & Omitted $^{e}$ & \\
\hline Pleural & $92(12.4)$ & $32(12.3)$ & $60(12.5)$ & $1.02(0.64-1.61)$ & 0.94 & Omitted $^{e}$ & \\
\hline Lymphatic & $309(41.8)$ & $76(29.2)$ & $233(48.5)$ & $2.28(1.65-3.17)$ & 0.0001 & Omitted $^{e}$ & \\
\hline Bone and/or joint & $13(1.8)$ & $2(0.8)$ & $11(2.3)$ & $3.03(0.66-13.8)$ & 0.155 & Omitted $^{e}$ & \\
\hline Genitourinary & $37(5.0)$ & $5(1.9)$ & $32(6.7)$ & $3.64(1.39-9.52)$ & 0.004 & Omitted $^{e}$ & \\
\hline Meningeal and other central nervous system & $74(10.0)$ & $28(10.8)$ & $46(9.6)$ & $0.88(0.53-1.44)$ & 0.608 & Omitted $^{e}$ & \\
\hline Gastro-intestinal & $55(7.4)$ & $16(6.2)$ & $39(8.1)$ & $1.35(0.74-2.46)$ & 0.329 & Omitted $^{e}$ & \\
\hline \multicolumn{8}{|l|}{ TB symptoms } \\
\hline Cough (yes vs no) & $501(67.7)$ & $188(72.3)$ & $313(65.2)$ & $0.72(0.52-0.99)$ & 0.049 & $0.72(0.51-1.02)$ & 0.061 \\
\hline Fever (yes vs no) & $636(86.0)$ & $227(87.3)$ & 409 (85.2) & $0.84(0.54-1.31)$ & 0.433 & & \\
\hline Weight loss (yes vs no) & $445(60.1)$ & $133(51.2)$ & $312(65.0)$ & $1.77(1.3-2.42)$ & 0.0001 & $1.63(1.18-2.24)$ & 0.003 \\
\hline \multicolumn{8}{|l|}{ Number of symptoms ${ }^{c}$} \\
\hline None & $20(2.7)$ & $6(2.3)$ & $14(2.9)$ & Ref & Ref & & \\
\hline One symptom & $133(18.0)$ & $50(19.2)$ & $83(17.3)$ & $0.71(0.26-1.97)$ & 0.512 & & \\
\hline Two symptoms & $312(42.2)$ & $114(43.9)$ & $198(41.3)$ & $0.74(0.28-2.0)$ & 0.556 & & \\
\hline Three symptoms & $275(37.2)$ & $90(34.6)$ & 185 (38.5) & $0.88(0.33-2.37)$ & 0.802 & & \\
\hline
\end{tabular}


Table 1 (continued)

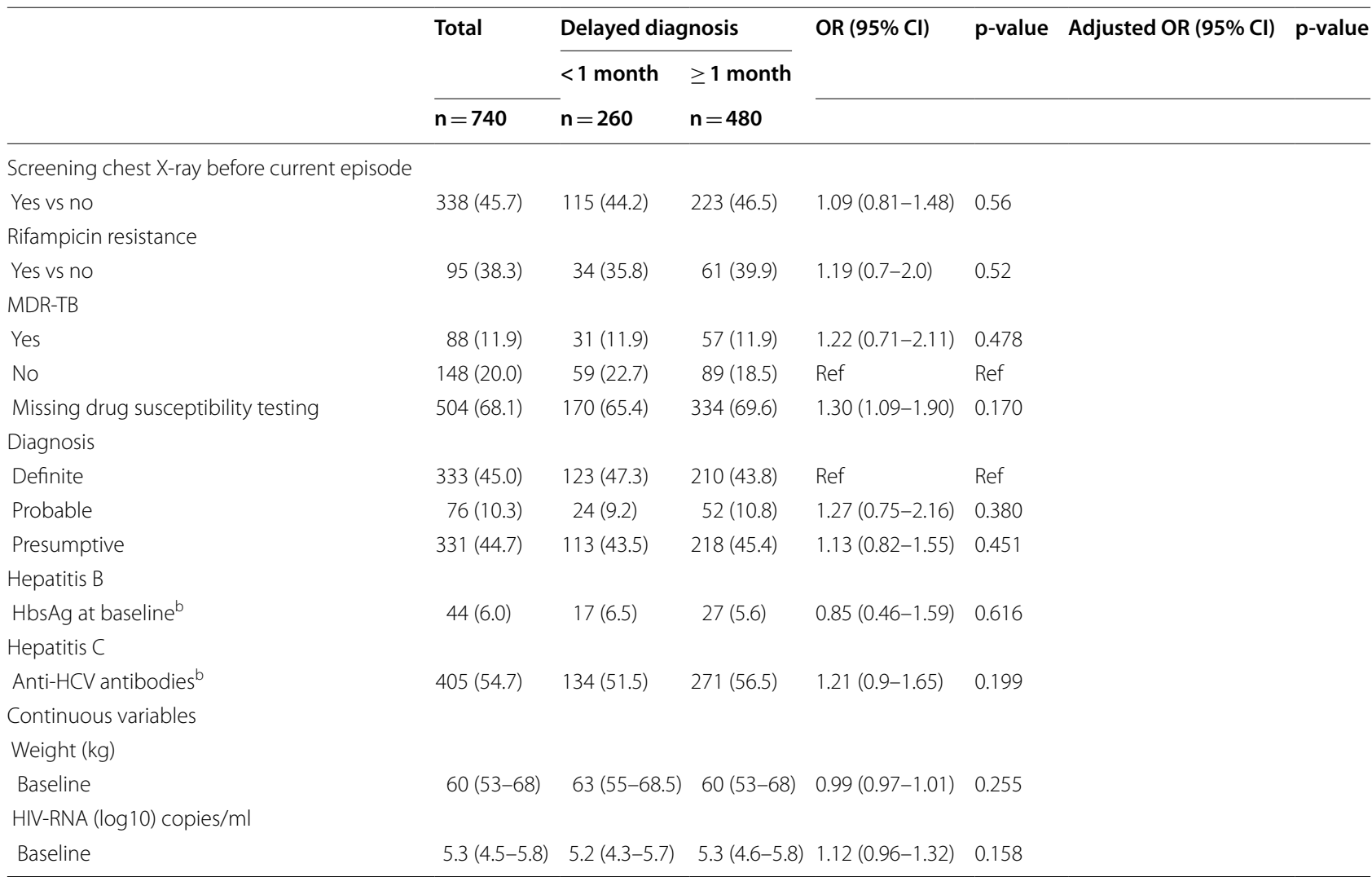

Adjusted for age, IDU, ART treatment naivety, cotrimoxazole treatment, previous TB, clinical TB presentation and TB symptoms cough and weight loss $O R$ odds ratio, $\mathrm{Cl}$ confidence interval, MSM Men Who Have Sex with Men, IDU injecting drug use

a Those not included in the categories "ART naïve at TB diagnosis" and"ART use at TB diagnosis" have previously received ART and interrupted their treatment

${ }^{b}$ Those with missing information for chest $x$-ray $(n=278), \operatorname{HBsAg}(n=215)$, Anti-HCV $(n=220)$ assumed negative

'Index based on symptoms cough, fever, weight loss

${ }^{d}$ Omitted because of multicollinearity with Treatment Naivety (correlation co-efficient 0.7817 )

e Omitted in model as part of extra-pulmonary/disseminated

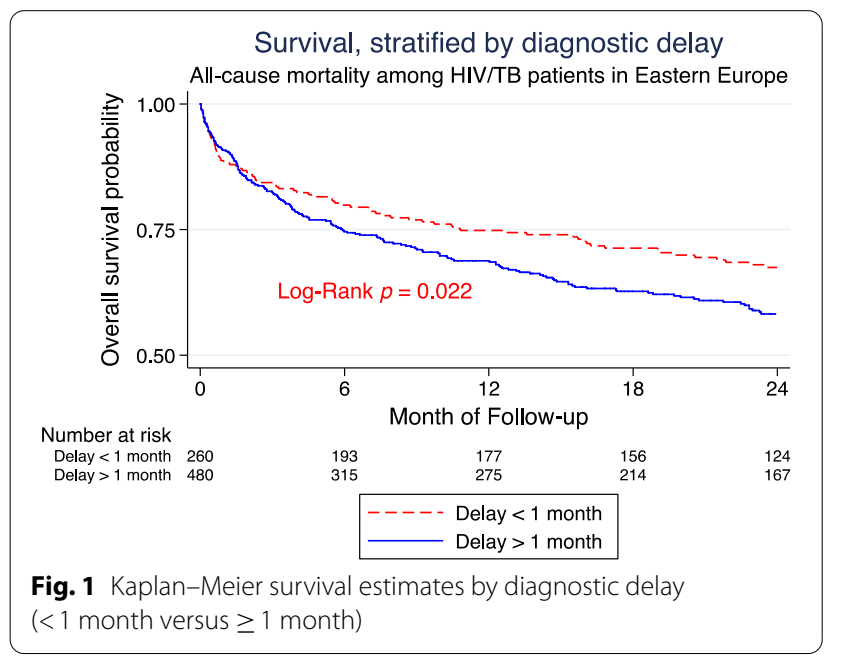

In the unadjusted Cox proportional hazard models for all-cause mortality with 24 months follow-up, PLWH with a delayed TB diagnosis were at $36 \%$ increased risk of death (hazard ratio 1.36; 95\% CI 1.04-1.77; $\mathrm{p}=0.023$ ). In the adjusted analysis, the estimate decreases only slightly (adjusted hazard ratio 1.27; 95\% CI 0.95-1.70; $\mathrm{p}=0.103$ ) (Table 2). At the same time, there is a clear association between increased risk of death and male sex, low or missing CD4 cell count, prior AIDS, disseminated TB disease, weight loss and MDR-TB (Table 2). Stratifying the Cox proportional hazards model for all-cause mortality at $0-2$ months and 2-24 months follow-up according to the appearance of the survival curves, no effect of delayed diagnosis on risk of death was observed for the first 2 months (aHR 1.09; 95\% CI 0.69-1.71; p=0.723), while the period 2-24 months seems to explain the observed overall effect (aHR 1.36; 95\% CI 0.93-1.99; $\mathrm{p}=0.119$ ) (Additional file 1: Tables S1 and S2). 
Table 2 Cox-regression model for survival in Eastern Europe, crude and adjusted hazard ratios (24 months follow-up)

\begin{tabular}{|c|c|c|c|c|c|}
\hline & Total $(n=740)$ & Crude HR $(95 \% \mathrm{Cl})$ & p-value & Adjusted HR $(95 \% \mathrm{Cl})^{\mathrm{a}}$ & $p$-value \\
\hline Delayed diagnosis & $\geq 1$ month $(n=480)$ & $1.36(1.04-1.77)$ & 0.023 & $1.27(0.95-1.70)$ & 0.103 \\
\hline Gender & Male $(n=563)$ & $1.34(1.02-1.76)$ & 0.032 & $1.38(1.04-1.83)$ & 0.026 \\
\hline \multirow[t]{2}{*}{ Age } & Age $18-49(n=694)$ & Ref & Ref & & \\
\hline & Age $\geq 50(n=46)$ & $0.92(0.55-1.52)$ & 0.741 & & \\
\hline \multirow[t]{3}{*}{ Exposure group (HIV) } & $\operatorname{MSM}(n=10)$ & $0.49(0.12-1.95)$ & 0.309 & & \\
\hline & $\operatorname{IDU}(n=422)$ & $1.19(0.93-1.52)$ & 0.173 & & \\
\hline & Heterosexual $(n=183)$ & $0.84(0.63-1.13)$ & 0.255 & & \\
\hline Known HIV positive & At baseline $(n=668)$ & $1.55(0.96-2.50)$ & 0.074 & $1.43(0.84-2.42)$ & 0.185 \\
\hline \multirow[t]{3}{*}{ Treatment history (HIV) } & Naïve at TB diagnosis ${ }^{\complement}(n=558)$ & $1.04(0.79-1.38)$ & 0.766 & & \\
\hline & ART at baseline ${ }^{c}(n=132)$ & $0.96(0.70-1.31)$ & 0.795 & & \\
\hline & Cotrimoxazole at baseline $(n=273)$ & $1.22(0.96-1.56)$ & 0.110 & & \\
\hline \multirow[t]{3}{*}{ CD4-cell count/mm $\mathrm{mm}^{3 \circ}$} & $0-199 / \mathrm{mm}^{3}(\mathrm{n}=440)$ & $2.17(1.53-3.09)$ & 0.001 & $1.84(1.27-2.68)$ & 0.001 \\
\hline & $\geq 200 / \mathrm{mm}^{3}(n=185)$ & Ref & Ref & Ref & Ref \\
\hline & Missing CD4 $(n=115)$ & $2.17(1.41-3.33)$ & 0.001 & $2.32(1.47-3.66)$ & 0.001 \\
\hline Prior AIDS & Yes $(n=177)$ & $1.87(1.45-2.41)$ & 0.001 & $1.69(1.27-2.24)$ & 0.001 \\
\hline Previous TB & Yes $(n=99)$ & $0.97(0.68-1.39)$ & 0.880 & & \\
\hline \multirow[t]{3}{*}{ TB risk factor } & Alcohol abuse $(n=186)$ & $1.32(1.01-1.73)$ & 0.041 & $1.24(0.92-1.68)$ & 0.158 \\
\hline & Recent TB in family ( $n=53$ ) & $0.84(0.50-1.42)$ & 0.524 & & \\
\hline & Prison within the last 2 years $(n=143)$ & $1.11(0.82-1.51)$ & 0.493 & & \\
\hline \multirow[t]{3}{*}{ Clinical presentation of TB } & Pulmonary $(n=239)$ & Ref & Ref & Ref & Ref \\
\hline & Extrapulmonary $(n=54)$ & $0.98(0.51-1.88)$ & 0.957 & $0.86(0.44-1.68)$ & 0.657 \\
\hline & Disseminated $(n=447)$ & $2.31(1.71-3.11)$ & 0.001 & $1.93(1.38-2.69)$ & 0.001 \\
\hline \multirow{3}{*}{ TB symptoms at diagnosis } & Cough $(n=501)$ & $0.95(0.74-1.23)$ & 0.708 & & \\
\hline & Fever $(n=636)$ & $1.59(1.07-2.37)$ & 0.022 & $1.41(0.91-2.19)$ & 0.124 \\
\hline & Weight loss $(n=445)$ & $1.70(1.31-2.21)$ & 0.001 & $1.41(1.05-1.88)$ & 0.022 \\
\hline \multirow[t]{4}{*}{ Number of symptoms§ } & None $(n=20)$ & Ref & Ref & & \\
\hline & One symptom $(n=133)$ & $0.89(0.38-2.11)$ & 0.793 & & \\
\hline & Two symptoms $(n=312)$ & $1.12(0.49-2.56)$ & 0.783 & & \\
\hline & Three symptoms $(n=275)$ & $1.58(0.69-3.58)$ & 0.277 & & \\
\hline Screening chest $X$-ray in past ${ }^{d}$ & Yes $(n=338)$ & $1.30(1.02-1.66)$ & 0.034 & $1.27(0.93-1.74)$ & 0.133 \\
\hline Rifampicin resistance & Yes $(n=95)$ & $1.53(1.12-2.10)$ & 0.007 & Omitted $^{b}$ & \\
\hline \multirow[t]{3}{*}{ MDR-TB } & Yes $(n=88)$ & $2.61(1.68-4.05)$ & 0.001 & $2.06(1.06-4.01)$ & 0.033 \\
\hline & No $(n=148)$ & Ref & Ref & Ref & \\
\hline & Missing $(n=504)$ & $1.84(1.28-2.64)$ & 0.001 & $1.32(0.68-2.57)$ & 0.407 \\
\hline \multirow[t]{3}{*}{ Diagnosis } & Definitive $(n=333)$ & Ref & Ref & Ref & Ref \\
\hline & Probable $(n=76)$ & $1.43(0.97-2.11)$ & 0.074 & $0.99(0.61-1.59)$ & 0.955 \\
\hline & Presumptive $(n=331)$ & $1.03(0.80-1.34)$ & 0.795 & $0.95(0.67-1.35)$ & 0.764 \\
\hline Hepatis B & HBsAg positive $(n=44)^{d}$ & $0.95(0.56-1.60)$ & 0.843 & & \\
\hline Hepatitis C & Anti-HCV positive $(n=405)^{d}$ & $1.20(0.94-1.53)$ & 0.145 & & \\
\hline Drug-susceptibility testing & At baseline $(n=236)$ & $0.84(0.65-1.08)$ & 0.175 & & \\
\hline Treatment with $\mathrm{RHZ}$ & At baseline $(n=591)$ & $0.81(0.59-1.09)$ & 0.157 & & \\
\hline Treatment with at least three active drugs & At baseline $(n=132)$ & $0.64(0.46-0.91)$ & 0.014 & $0.81(0.52-1.25)$ & 0.344 \\
\hline
\end{tabular}

HR hazard ratio, Cl confidence interval, MSM Men Who Have Sex with Men, IDU injecting drug use Global Test Proportional Hazard Assumption $p=0.3689$, individually all $>0.05$

${ }^{a}$ Adjusted for diagnostic delay, gender, known HIV positive, CD4 cell count, prior aids, tb risk factor alcohol, clinical presentation (all), Tb symptoms (fever, weight loss), chest $\mathrm{x}$-ray, MDR-TB, type of diagnosis, treatment with at least three active drugs, stratified by Center

${ }^{\mathrm{b}}$ Omitted Rifampicin resistance in the multivariable model due to multicollinearity with MDR-TB

"Those not included in the categories "ART naïve at TB diagnosis" and"ART use at TB diagnosis" have previously received ART and interrupted their treatment

${ }^{d}$ Those with missing information for chest $x$-ray $(n=278), \operatorname{HBsAg}(n=215)$, Anti-HCV $(n=220)$ assumed negative

$\S$ Index based on symptoms cough, fever, weight loss 


\section{Sensitivity analysis}

Of all 262 deaths within 24 months, 97 (37.0\%) were directly TB-related. In an adjusted Cox proportional hazards model for TB-related mortality within 24 months follow-up delayed diagnosis had no effect on TB-related death (aHR 1.00; 95\% CI 0.62-1.59; $\mathrm{p}=0.988$ ).

When stratifying delayed diagnosis by $\leq 3$ months $(\mathrm{n}=640)$ versus $>3$ months $(\mathrm{n}=100)$, at 24 months 247 (38.6\%) deaths had occurred in the group of $\leq 3$ months and $59(59 \%)$ in the group of $>3$ months. Kaplan-Maier survival analysis showed no difference in survival function (log-rank $\mathrm{p}=0.777$ ) (Additional file 1$)$.

In an adjusted Cox proportional hazards model with 24 months of follow-up there was no effect of a delayed diagnosis for more than three months on all-cause mortality (aHR 1.00; 95\% CI 0.7-1.45; $\mathrm{p}=0.986$ ).

\section{Discussion}

In the present study, we found older age ( $\geq 50$ years), IDU, ART naivety, disseminated TB and presenting with weight loss were associated with delayed diagnosis, while a previous TB diagnosis was associated with a lower risk of late diagnosis. Furthermore, a delayed TB diagnosis was associated with an increased risk for all-cause death in PLWH in Eastern Europe. Our study provides indication for a systematic screening and active case finding in PLWH at risk of delayed TB diagnosis.

\section{Factors associated with delayed diagnosis in PLWH}

Our study is the first to present factors associated with delayed TB diagnosis in PLWH in Eastern Europe. Some of the factors identified in the present study, such as older age, being ART naive and IDU have been identified in other settings. In a South African cohort including only PLWH with pulmonary TB older age ( $>40$ years) and HIV-RNA viral load $>400$ copies $/ \mathrm{ml}$ were predictors for delayed diagnosis, while being on ART at time of diagnosis was associated with lower risk of delayed diagnosis [20]. A study including all drug-susceptible TB cases in PLWH from Colombia found age between 15-34, age $\geq 45$ years, and receiving tuberculin skin tests as a part of the diagnostic work-up associated with delayed diagnosis [21]. In a Brazilian cohort of 242 PLWH with $\mathrm{TB}$, factors associated with patient delay were the symptoms asthenia, chest pain, and the use of illicit drugs, including IDU [22]. In this current study, we identified a previous TB diagnosis as associated with lower risk of delayed diagnosis, which is in line with another cohort of PLWH from Brazil [23]. Weight loss and disseminated disease have not been previously described as associated with delayed diagnosis which could be due to better ascertainment of the symptom weight loss and disseminated disease presentation in our study or to uncontrolled circularity.

In patients diagnosed with TB (without HIV) in Kiev city long diagnostic delay was reported by individuals who were homeless, jobless or abused alcohol [24]. In Uzbekistan TB mono-infected patients self-medication, coughing, loss of weight, and visiting private and primary healthcare facilities were associated with delay [25]. Similar results were observed in Georgia where receipt of medication prior to TB diagnosis was associated with increased overall delayed diagnosis [26].

Disseminated TB was associated with delayed diagnosis in the present analysis. These diagnostic challenges have been described previously in PLWH as the extrapulmonary or disseminated TB presentation makes it difficult to obtain suitable specimen for culture [27, 28].

\section{Effect of delayed diagnosis on survival in PLWH}

In our study, those with a delayed diagnosis of at least 1 month had a $36 \%$ higher risk of dying within the first 2 years after the TB diagnosis. Compared to previous studies in other settings the effect seems less pronounced, and when adjusting for other patient characteristics, the result was no longer insignificant, although the effect size remains similar and the upper limit of the $\mathrm{CI}$ suggests it could be a quite large effect. Furthermore, there is a clear association between increased risk of death and male sex, low or missing CD4 cell count, prior AIDS, disseminated TB disease, weight loss and MDR-TB; all of which have been found and described in a previous study of the current cohort [17]. In a retrospective cohort of PLWH with pulmonary TB in China, a delayed diagnosis of more than 1 month from onset of symptoms increased the risk of death almost three-fold (aHR 2.60; 95\% CI 1.42-4.78) [29]. In a Brazilian study, PLWH with TB who had previously started on ART, duration of TB symptoms over 3 months before diagnosis increased the risk of death six-fold ( $\mathrm{HR}=6.15,95 \%$ CI 1.15-32.9) [14]. In Malawi, seeking care after more than 1 month or 3 months was associated with an increased risk of death of about $60 \%$ (aHR 1.6, 95\% CI 0.9-2.8) and 100\% (aHR 2.0, 95\% CI $1.1-3.8)$, respectively [30]. On the contrary, a Thai study of 667 PLWH with TB found no effect of delayed TB diagnosis on survival [31].

Supplementary survival analyses stratified by followup time suggest that delayed diagnosis has no effect on survival during the first 2 months after TB treatment initiation, but seem to have an effect beyond 2 months after initiation of TB treatment, albeit insignificantly so, perhaps due to limited number of patients in the study. In our study, mortality was very high during the first 2 months, which leads us to speculate that those 
presenting with shorter symptom duration might be suffering from quickly progressing disease with worse early outcomes. That suggests that other factors were driving the mortality in the first 2 months diluting the effect of delayed diagnosis on survival in the early period. These could be factors such as disseminated disease, MDR-TB and an AIDS diagnosis which also are significant predictors of mortality in the stratified analysis $0-2$ months (Additional file 1: Table S1).

\section{Potential implications for policy and research}

It is very likely that better integration of clinical services and diagnostic capacity can decrease delays in diagnosing TB in PLWH. HIV and TB services in Eastern Europe are only provided in one place at about $36 \%$ of health care centers [32]. While evidence of the effect of integrated health care on delayed diagnosis is not available, studies in Sub-Saharan Africa have shown improved HIV and TB treatment outcomes when integrating HIV and TB care $[33,34]$.

Furthermore, strengthening diagnostic capacity for sputum-smear negative and extra-pulmonary TB (i.e., molecular diagnostic tests such as Xpert) are crucial as TB in PLWH often presents as extrapulmonary or disseminated $\mathrm{TB}$ and is commonly sputum-smear negative. There is evidence from Mozambique, where PLWH delayed for TB diagnosis due to initial negative sputum smear microscopy but consecutive positivity (Xpert TB test) had a 12-fold higher mortality, reiterating the importance of rapid diagnostics [16]. In Rwanda, expanded access to systematic Xpert testing and standardized treatment of Rifampicin-resistant TB in both HIV-seronegative and PLWH led to the reduction of diagnostic and treatment delays resulting in reduced mortality [35]. In Eastern Europe, Xpert was used as part of routine workup at almost all (92\%) clinics in 2018, which is a major improvement compared to 2013 (54\%) when the present study was conducted, so we cannot rule out improvements to delayed diagnosis in the meantime [32]. A promising additional tool for rapid diagnosis and treatment initiation at the point of care for PLWH regardless of site of TB infection is the urine-based lipoarabinomannan (LAM) test [36]. Further prospective studies of this intervention and its effect on delayed diagnosis, in particular in an Eastern European context, are needed.

In addition to improving health care infrastructure, active case finding among high-risk populations, in our study those of older age, people who inject drugs and PLWH not on ART, may help reduce delayed diagnoses and improve linkage to health care [37]. In an active pulmonary TB case finding study among newly HIV diagnosed patients in Tbilisi, Georgia, $11.5 \%$ of patients were identified with pulmonary TB, highlighting the utility of an active case finding strategy [38]. Periodic screening for TB among PLWH using symptoms, chest $\mathrm{x}$-ray, Xpert and/or urine-LAM point-of-care testing according to WHO guidelines could improve case finding [39]. However, to the best of our knowledge no evidence on the systematic implementation of these guidelines in Eastern Europe and Central Asia exists.

Our study has some limitations. First, the generalizability of our results to the background/general population may be impaired due to selection bias, as recruitment to our study is conditional on both TB and HIV being diagnosed. Those who were never diagnosed with TB or HIV due to early death without making contact to health care were not included. However, these patients presumably would have worse outcomes and a long diagnostic delay if included here, as reduced access to health care is likely associated with similar risk factors as delayed diagnosis, morbidity and mortality. Therefore, our results likely underestimate the effect of delayed diagnoses on mortality in the population. Secondly, Eastern Europe is heterogeneous, delay of diagnosis may vary within the region and in some countries, health care has improved since the period of data collection in 2013 [32]. As drug susceptibility testing was not widely available in Eastern Europe at the time of the study and those without testing results were assumed susceptible our study very likely underestimated MDR-TB and has led to increased mortality. Thirdly, we cannot rule out a certain degree of circularity in the analysis of risk factors for delayed diagnosis; e.g., disseminated disease or weight loss can be risk factors for delayed diagnosis due to an unexpected or hard to diagnosis disease presentation but they can also be a consequence of delayed diagnosis. Finally, for most patients in the present study the date of TB diagnosis and of treatment initiation were identical. Therefore, we were not able to calculate the health care delay, the time span between diagnosis and treatment initiation.

Regardless, the current study adds important knowledge to the field of health care for TB/HIV co-infection in Eastern Europe.

\section{Conclusions}

We found that nearly two thirds of PLWH with TB in Eastern Europe had a delayed TB diagnosis, in particular those of older age, people who inject drugs, ART naïve, with disseminated disease, and presenting with weight loss. Patients with delayed TB diagnosis were subsequently at higher risk of death in unadjusted analysis. There is a clear need for optimization of the current TB diagnostic cascade and HIV care in PLWH in Eastern Europe to reduce delayed diagnoses to reduce morbidity and improve treatment outcomes. While health care planners and policy makers should ensure strengthened 
diagnostic capacity, clinicians should pay special attention to patient groups identified as being at higher risk for delayed TB diagnosis, and further research should focus on developing more effective diagnostic interventions to reduce delayed diagnoses.

\section{Appendix TB:HIV Study Group}

www. chip.dk/Resea rch / Studi es / TBHIV/ TBHIV-Study-Group

The Study Group consists of the following 62 participating sites in 19 countries (listed with countries, names of participating centers).

A. Vassilenko ${ }^{14}$, D. Klimuk ${ }^{15}$, O. Kondratenko ${ }^{15}$, A. Zalutskaya ${ }^{15}$, V. Bondarenko ${ }^{16}$, V. Mitsura ${ }^{16}$, E. Kozorez $^{16}$, O. Tumash ${ }^{16}$, O. Suetnov ${ }^{17}$, D. Paduto ${ }^{17}$, V. Iljina $^{18}$, T. Kummik ${ }^{18}$, K. Mshvidobadze ${ }^{19}$, N. Lanchava ${ }^{19}$, L. Goginashvili ${ }^{20}$, L. Mikiashvili ${ }^{20}$, N. Bablishvili ${ }^{20}$, B. Rozentale ${ }^{21}$, I. Zeltina ${ }^{21}$, I. Janushkevich ${ }^{21}$, I. Caplinskiene $^{22}$, S. Caplinskas ${ }^{22}$, Z. Kancauskiene ${ }^{22}$, A. Wiercinska-Drapalo ${ }^{23}$ M. Thompson ${ }^{24}$, J. Kozlowska ${ }^{24}$, A. Grezesczuk ${ }^{24}$, M. Bura ${ }^{25}$ B. Knysz ${ }^{26}$, M. Inglot ${ }^{26}$, A. Garlicki ${ }^{27}$, J. Loster ${ }^{27}$, D. Duiculescu ${ }^{28}$, A. Rakhmanova ${ }^{29}$, O. Panteleev ${ }^{29}$, A. Yakovlev ${ }^{29}$, A. Kozlov $^{29}$, A. Tyukalova ${ }^{29}$, Y. Vlasova ${ }^{29,30}$, T. Trofimov ${ }^{31}$, G. Kyselyova ${ }^{32}$, N. Obel $^{33}$, J. Gerstoft ${ }^{33}$, G. Kronborg ${ }^{34}$, MC Payen ${ }^{35}$, K. Kabeya ${ }^{35}$, C. Necsoi ${ }^{35}$, F. Dabis ${ }^{36}$, A. Tsaranazy $^{36}$, C. Cazanave ${ }^{37}$, H. Furrer ${ }^{38}$, M. Sagette ${ }^{38}$, M. Rickenbach $^{38}$, D. Sculier ${ }^{39}$, A. Calmy ${ }^{39}$, M. Cavassini ${ }^{40}$, A. Bruno $^{41}$, E. Bernasconi ${ }^{41}$, M. Hoffmann ${ }^{42}$, P. Vernazza ${ }^{42}$, J. Fehr ${ }^{43}$, R. Weber ${ }^{43}$, R. Miller ${ }^{44}$, N. Vora ${ }^{44}$, G. Cooke ${ }^{45}$, S. Mullaney ${ }^{45}$, E. Wilkins ${ }^{46}$, V. George ${ }^{46}$, P. Collini ${ }^{47}$, D. Dockrell ${ }^{47}$, F. Post ${ }^{48}$, L. Campbell ${ }^{48}$, R. Brum ${ }^{48}$, E. Mabonga $^{48}$, P. Saigal ${ }^{48}$, S. Kegg ${ }^{49}$, J. Ainsworth ${ }^{50}$, A. Waters $^{50}$ J. Dhar ${ }^{51}$, K. Ellis ${ }^{51}$, E. Girardi ${ }^{52}$, A Rianda ${ }^{52}$, V. Galati $^{52}$, C. Pinnetti ${ }^{52}$, C. Tommasi ${ }^{52}$, G. Lapadula ${ }^{53}$, A. Di Biagio ${ }^{54}$, A. Parisini ${ }^{54}$, S. Carbonara ${ }^{55}$, G. Angarano ${ }^{55}$, M. Purgatorio ${ }^{55}$, A. Matteelli ${ }^{56}$, A. Apostoli ${ }^{56}$, JM. Miro $^{57}$, C. Manzardo ${ }^{57}$, C. Ligero ${ }^{57}$, J. Gonzalez ${ }^{57}$, Jose A. Martinez-Martinez ${ }^{57}$, F. Sanchez ${ }^{58}$, H. Knobel ${ }^{58}$, M. Salvadó $^{58}$, J.L. Lopez-Colomes ${ }^{58}$, X. Martínez-Lacasa ${ }^{59}$, E. Cuchí ${ }^{59}$, V. Falcó ${ }^{60}$, A. Curran ${ }^{60}$, M.T. Tortola ${ }^{60}$, I. Ocaña $^{60}$, R. Vidal ${ }^{60}$, MA. Sambeat ${ }^{61}$, V. Pomar $^{61}$, P. Coll $^{61}$, D. Pozamczer $^{62}$, M. Saumoy ${ }^{62}$, F. Alcaide ${ }^{62}$, J. Caylà ${ }^{63}$, A. Moreno ${ }^{63}$, J.P. Millet ${ }^{63}$, A. Orcau ${ }^{63}$, L. Fina ${ }^{63}$, A. Romero $^{63}$, L.L. Roldan ${ }^{63}$, JA. Iribarren ${ }^{64}$, M. Ibarguren ${ }^{64}$, S. Moreno ${ }^{65}$, A. González ${ }^{65}$, P. Miralles ${ }^{66}$, T. AldámizEchevarría $^{66}$, M. Losso ${ }^{67}$, J. Toibaro ${ }^{67}$, L. Gambardella ${ }^{67}$, J. Toibaro $^{68}$, L. Moreno Macias ${ }^{68}$, E. Warley ${ }^{69}$, S. Tavella ${ }^{69}$, O. Garcia Messina ${ }^{70}$, O. Gear ${ }^{70}$, H. Laplume ${ }^{71}$, C. Marson $^{72}$, J. Contarelia ${ }^{73}$, M. Michaan ${ }^{73}$, P. Scapellato ${ }^{74}$, B. Bartoletti ${ }^{75}$, D. Palmero ${ }^{75}$, C. Elias $^{76}$, C. Cortes ${ }^{77}$, B.
Crabtree $^{78}$, JL Mosqueda Gomez ${ }^{79}$, J. A. Villanueva ${ }^{80}$; LA Gonzalez Hernandez ${ }^{80}$ and F. Badial ${ }^{80}$.

14 Belarusian State Medical University, Department of Infectious Disease.

15 Republican Research and Practical Centre for Pulmonology.

16 Gomel State Medical University (Gomel).

17 Gomel Region Centre for Hygiene: O. Suetnov (PI) and D. Paduto.

18 East Viru Central Hospital (Kohtla-Jarve), Estonia.

19 Infectious Diseases, AIDS and Clinical Immunology

Research Center (Tiblisi).

20 National Center for Tuberculosis and Lung Diseases of Georgia (Tibilisi).

21 Infectology Centre of Latvia (Riga).

22 Centre for Communicable Diseases and AIDS (Vilnius).

23 Wojewodski Szpital Zakanzy/Medical University of Warsaw (Warszawa).

24 Wojewodski Szpital Specjalistyczny/Medical University Teaching Hospital (Bialystok).

25 Jozef Strus Multidisciplinary City Hospital (Poznan). 26 Wroclaw University School of Medicine (Wroclaw).

27 Jagiellonian University Medical College (Krakow).

28 Dr. Victor Babes Hospital (Bucharest).

29 Botkin Hospital of Infectious Diseases (St. Petersburg).

30 City TB Hospital No. 2 (St. Petersburg):

31 Center for Prevention and Control of AIDS (Veliky, Novgorod).

32 Crimean Republican AIDS Centre (Simferopol).

33 Rigshospitalet (Cph).

34 Hvidovre University Hospital.

35 CHU Saint-Pierre (Brussels).

36 Aquitaine Cohort.

37 Bordeaux University Hospital.

38 University Hospital Bern.

39 Hopital Cantonal Universitaire, Geneve.

40 Centre Hospitalaire Universitaire Vaudois, Lausanne.

41 Hospital of Lugano.

42 Cantonal Hospital St. Gallen.

43 University Hospital Zurich.

44 Mortimer Market Centre (London).

45 St. Mary's Hospital.

46 North Manchester General Hospital.

47 Sheffield Teaching Hospitals.

48 King's College Hospital (London).

49 Queen Elizabeth Hospital.

50 North Middelsex University Hospital.

51 Leicester Royal Infirmary.

52 IRCCS-Ospedale L. Spallanzani (Rome).

53 AO San Gerardo (Monza). 


\author{
54 IRCCS AOU San Martino - IST di Genoa \\ (Genova). \\ 55 Clinic of Infectious Diseases, University of Bari \\ (Bari). \\ 56 University of Brescia Spedali Civili. \\ 57 Hospital Clinic of Barcelona. \\ 58 Hospital del Mar. \\ 59 Mutua de Terrassa. \\ 60 Hospital Universitari Vall d'Hebrón: \\ 61 Hospital Universitari de la Santa Creu i Sant Pau. \\ 62 Hospital Universitari de Bellvitge. \\ 63 Agencia de Salud Pública de Barcelona. \\ 64 Hospital Universitaria Donostia (San Sebastian). \\ 65 Hospital Ramon y Cajal (Madrid). \\ 66 Hospital Universitaria'Gregorio Marañon" (Madrid). \\ 67 The CICAL Cohort, Argentina. \\ 68 Hospital J. M. Ramos Mejía (Buenos Aires). \\ 69 Hospital Paroissien (BA). \\ 70 Hospital Piñero (BA). \\ 71 Hospital Nacional Profesor Alejandro Posadas: \\ 72 Hospital Rawson (Cordoba). \\ 73 Hospital San Juan de Dios (La Plata). \\ 74 Hospital General de Agudos Donación F. Santojani. \\ 75 Hospital Francisco Javier Muñiz (BA). \\ 76 Hospital Jujuy. \\ 77 Fundación Arriaran (Santiago). \\ 78 INNcMZS (México DF). \\ 79 Hospital General Regional de Leon- CAPACITS. \\ 80 Hospital Civil de Guadalajara.
}

\begin{abstract}
Abbreviations
TB: Tuberculosis; HIV: Human immunodeficiency virus; PLWH: People living with HIV; AIDS: Acquired immunodeficiency syndrome; IEC: Independent Ethics Committee; IRB: Institutional Review Board; RNA: Ribonucleotide acid; ART: Antiretroviral therapy; HBsAg: Hepatitis B surface antigen; HCV: Hepatitis C virus; MDR: Multi-drug resistant; PCR: Polymerase chain reaction; Mtb: Mycobacterium tuberculosis; CSF: Cerebrospinal fluid; KM: Kaplan-Meier; HR: Hazard ratio; Cl: Confidence interval; IDU: Injecting drug use; OR: Odds ratio; PYFU: Person years of follow-up; LAM: Lipoarabinomannan.
\end{abstract}

\section{Supplementary Information}

The online version contains supplementary material available at https://doi. org/10.1186/s12879-021-06745-w.

Additional file 1: Table S1. Cox-regression model for survival in Eastern Europe, crude and adjusted hazard ratios for follow-up 0-2 months. Table S2. Cox-regression model for survival in Eastern Europe, crude and adjusted hazard ratios for follow-up 2-24 months. Figure S1. Kaplan-Meier survival estimates by diagnostic delay ( $\leq 3$ months versus $>3$ months)

\section{Acknowledgements}

Not applicable.

\section{Guidelines}

The STROBE guidelines for cohort studies were followed in the conduct of this study.

\section{Authors' contributions}

CK, OK and AM conceived of the study. AP, IA, AS, NB, ST, RP, IK, EB, ED, JL, DP contributed to data collection. CK did statistical analysis. CK, AB, AM, OK, $\mathrm{DP}$ and ISJ contributed to interpretation of data analysis. All authors were involved in drafting the final manuscript. All authors read and approved the final manuscript.

\section{Funding}

Open Access funding enabled and organized by Projekt DEAL.

\section{Availability of data and materials}

The datasets used and/or analyzed during the current study are available from the corresponding author on reasonable request.

\section{Declarations}

\section{Ethics approval and consent to participate}

Informed consent was obtained from all participants. All methods were carried out in accordance with relevant guidelines and regulations. In specific, IEC/IRB were obtained from the following commitees: Le Comité d'Ethique du C.H.U Saint-Pierre, Le Numéra registre AK/12-0328/4128, Comité.

Ético Cientifico del servicio de Salud Metropolitano Centra, Chil, certificado 452/11, De.

Videnskabsetiske Komiteer i Region Hovedstaden Journal nr.: H-3-2011-095, United Kingdom national ethics approval Reference nr. 11/LO/0713 \& R\&D Reference nr. CSP 75430 for UK sites: Mortimor Market Centre, London, Imperial College Healthcare, London, St. Marys Hospital, London, North Manchester General Hospital, Manchester, Sheffield Teaching Hospitals, Sheffield, King's College Hospital, London, North Middlesex University Hospital, London, Queen Elisabeth Hospital, London R\&D ref. nr. SLHT/2011/UCSM/HIV/88, Leicester Royal Infirmary, Leicester. El Comité de Etica en Investigación en Salud, Hospital Paroissien Argentina 20/12/2911, Comité de Etica Iniciativa y Reflextion Bioetica Hospital Pineiro \& Hospital Ramos Mejia Argentina 12/12/12, Comité de Bioética Reg. nr. 11,743/11 Hospital Nacional Profesor Alejandro Posdas Argentina, Comité Institucional de Ėtica de la Investigacion en Salud del Nino u del Adulto Cordoba 16/12/2012 Hospital Rawson, Comité de Etica La Plata 12/11/12 Hospital Sa Juan de Dios Argentina, Comité de Ética en Investigacion Buenos Aires 18/11/12 Hospital Santojani Argentina \& 11/05/2012 Hospital Fracisco Javier Muniz Argentina, Docencia e Investigación 15/06/12 Jujuy Argentina, Institutional Review Board Tbilisi Ref. nr. 12-007, Registro delle Sperimentazioni del Comitato Etico Rone nr. 24/2011 Spallanzani, Comitato Etico San Gerardo, Monza 26/05/2011, Comitato Etico Aziendale A.O.U. San Martino Genoa nr. 295 08/04/2011, Comitato Etico Indipendente Locale Policlinio Consorziale Bari nr. 624 28/09/2011, Instituto Nacional de Ciencias Médicas y Nutrición Salvador Zubirán Ref. nr 437, Comité de Ética del Hospital General Regional de León 10/10/2011, Secretario del Comité de Ensenanza, Investigacion y Ética Hospital Civil de Guadalajara Invest. Nr. 038/12, Comitato Etico Spedali Civili Brescia 07/06/2011 nr.36; Direcció General de Regularcio Barcelona CY-ANT-2011-01, Hospital Universitario Ramón y Cajal Comité Ético de Investigación Clinica 12/07/2011, Comite Etico de Investigation Clinica de Euscadi Vitoria 02/02/2012, Comité Ético de Investigación Clínica Hospital General Universitario Gregorio Maranon Madrid SAS/3470/2009, Kantonale Ethik-Kommission Zürich EK-793, Ethical Committee of Rep. Res. And Practical Centre for Pulmonology Minsk 11/02/2011, Ethical Committee of Gomel State Medical University \& Gomel Regional Centre for Hygiene, Ethical Committee for Botkin Hospital \& City TB Hospital ref. nr.23, Ethical Committee for Novgorod Centre for AIDS Prevention and Control 11/10/2011, Ethican Committee of Samara State Medical University 10/10/2012, Komisja Bioetycznego Uniwersytetu Medycznego w Bialymstoku Poland R-I-00/85c/2012 -R-I-002/85/2011, Tallinn Medical Research Ethics Committee Appr. Nr. 2555, RSU Etikas Komitejas Lemums Riga Nr. E-9(2), Vilniaus Regioninis Biomedicininiu Tyrimu Etikos Komitetas Nr. 158,200-07363-90, Dr. Victor Babes Hospital Institutional Ethics Committee nr. 3889, Ethics Committee Crimean Republican AIDS Centre Nr. 462-13-08-12.

The data storage and handling was protected in accordance with and approved by the Danish Data Protection Agency (Datatilsynet) under the Act on Processing of Personal Data (Act No. 429 of 31 May 2000) and European Commission Directive 95/46/EC. http://www.chip.dk/Portals/0/files/Study\% 20documents/HIV_TB_project_protocol_2011.pdf. 


\section{Consent for publication \\ Not applicable.}

\section{Competing interests}

AM reports consulting fees by ViiV, Gilead, Eiland and Bonnin PC outside of the submitted work. RP reports fees for lectures and travel by Gilead sciences Poland outside of the submitted work. OK reports fees for consultation and travel by Gilead, Janssen, Merck and Viiv outside the submitted work. All other authors declare that they have no conflict of interest.

\section{Author details}

${ }^{1} \mathrm{CHIP}$ (Centre of Excellence for Health, Immunity and Infections), Rigshospitalet, University of Copenhagen, Copenhagen, Denmark. ${ }^{2}$ Department of Infectious Diseases, The Heart Centre, Rigshospitalet, University of Copenhagen, Copenhagen, Denmark. ${ }^{3}$ City TB Dispensary, St. Petersburg, Russia. ${ }^{4}$ Republican Scientific and Practical Center for Pulmonology and Tuberculosis, Minsk, Belarus. ${ }^{5}$ Infectious Diseases, AIDS and Clinical Immunology Research Center, Tbilisi, Georgia. 'Dr Victor Babes' Hospital of Tropical and Infectious Diseases, Bucharest AND 'Carol Davila' University of Medicine and Pharmacy, Bucharest, Romania. ${ }^{7}$ Wojewodski Szpital Zakanzy/Medical University of Warsaw, Warsaw, Poland. ${ }^{8}$ Department of Infectious Disease, Belarusian State Medical University, Minsk, Belarus. ${ }^{9}$ Samara State Medical University of the Ministry of Healthcare of the Russian Federation, Samara, Russia. ${ }^{10}$ Botkin Hospital of Infectious Disease, St. Petersburg, Russia. ${ }^{11}$ Riga East University Hospital, Latvian Centre of Infectious Diseases, Riga, Latvia. ${ }^{12}$ Research Unit for Infectious Diseases, Odense University Hospital, University of Southern, Odense, Denmark. ${ }^{13}$ Centre for Clinical Research, Epidemiology, Modelling and Evaluation (CREME), Institute for Global Health, UCL, London, UK. ${ }^{14}$ Heidelberg Institute of Global Health, University of Heidelberg, Heidelberg, Germany.

Received: 13 April 2021 Accepted: 20 Auqust 2021 Published online: 06 October 2021

\section{References}

1. World Health Organization. Global tuberculosis report 2020. Geneva: World Health Organization; 2020.

2. Ford N, Matteelli A, Shubber Z, Hermans S, Meintjes G, Grinsztejn B, et al. TB as a cause of hospitalization and in-hospital mortality among people living with HIV worldwide: a systematic review and meta-analysis. J Int AIDS Soc. 2016;19(1):20714.

3. Gupta RK, Lucas SB, Fielding KL, Lawn SD. Prevalence of tuberculosis in post-mortem studies of HIV-infected adults and children in resource-limited settings: a systematic review and meta-analysis. AIDS. 2015:29(15):1987-2002.

4. Getnet F, Demissie M, Assefa N, Mengistie B, Worku A. Delay in diagnosis of pulmonary tuberculosis in low-and middle-income settings: systematic review and meta-analysis. BMC Pulm Med. 2017;17:202.

5. Storla DG, Yimer S, Bjune GA. A systematic review of delay in the diagnosis and treatment of tuberculosis. BMC Public Health. 2008;14(8):15.

6. Tedla K, Medhin G, Berhe G, Mulugeta A, Berhe N. Delay in treatment initiation and its association with clinical severity and infectiousness among new adult pulmonary tuberculosis patients in Tigray, northern Ethiopia. BMC Infect Dis. 2020;20(1):456

7. Bajehson M, Musa BM, Gidado M, Nsa B, Sani U, Habibu AT, et al. Determinants of mortality among patients with drug-resistant tuberculosis in northern Nigeria. PLoS ONE. 2019;14(11):e0225165.

8. Jørstad MD, Aßmus J, Marijani M, Sviland L, Mustafa T. Diagnostic delay in extrapulmonary tuberculosis and impact on patient morbidity: a study from Zanzibar. PLoS ONE. 2018;13(9):e0203593.

9. Lin Y, Enarson DA, Du J, Dlodlo RA, Chiang C-Y, Rusen ID. Risk factors for unfavourable treatment outcome among new smear-positive pulmonary tuberculosis cases in China. Public Health Action. 2017;7(4):299-303.

10. Virenfeldt J, Rudolf F, Camara C, Furtado A, Gomes V, Aaby P, et al. Treatment delay affects clinical severity of tuberculosis: a longitudinal cohort study. BMJ Open. 2014;4(6):e004818.

11. Golub JE, Bur S, Cronin WA, Gange S, Baruch N, Comstock GW, et al. Delayed tuberculosis diagnosis and tuberculosis transmission. Int J Tuberc Lung Dis. 2006;10(1):24-30.
12. Lin X, Chongsuvivatwong V, Lin L, Geater A, Lijuan R. Dose-response relationship between treatment delay of smear-positive tuberculosis patients and intra-household transmission: a cross-sectional study. Trans R Soc Trop Med Hyg. 2008;102(8):797-804

13. WHO $\mid \mathrm{WHO}$ end TB strategy. WHO. World Health Organization. http:// www.who.int/tb/post2015_strategy/en/. Accessed 5 Aug 2020.

14. Schmaltz CAS, Santoro-Lopes G, Lourenço MC, Morgado MG, Velasque LdS, Rolla VC. Factors impacting early mortality in tuberculosis/HIV patients: differences between subjects naïve to and previously started on HAART. PLOS ONE. 2012;7(9):e45704.

15. Finnie RKC, Khoza LB, van den Borne B, Mabunda T, Abotchie P, Mullen $P D$. Factors associated with patient and health care system delay in diagnosis and treatment for TB in sub-Saharan African countries with high burdens of TB and HIV. Trop Med Int Health. 2011;16(4):394-411.

16. Lisboa M, Fronteira I, Colove E, Nhamonga M, Martins MdRO. Time delay and associated mortality from negative smear to positive Xpert MTB/ RIF test among TB/HIV patients: a retrospective study. BMC Infect Dis. 2019;19(1):18.

17. Podlekareva DN, Efsen AMW, Schultze A, Post FA, Skrahina AM, Panteleev A, et al. Tuberculosis-related mortality in people living with HIV in Europe and Latin America: an international cohort study. Lancet HIV. 2016;3(3):e120-31.

18. von Elm E, Altman DG, Egger M, Pocock SJ, Gøtzsche PC, Vandenbroucke $J$, et al. The Strengthening the Reporting of Observational Studies in Epidemiology (STROBE) statement: guidelines for reporting observational studies. Lancet. 2007;370(9596):1453-7.

19. Efsen AMW, Schultze A, Miller RF, Panteleev A, Skrahin A, Podlekareva DN, et al. Management of MDR-TB in HIV co-infected patients in Eastern Europe: results from the TB:HIV study. J Infect. 2018;76(1):44-54.

20. Boniface R, Moshabela M, Zulliger R, MacPherson P, Nyasulu P. Correlates of delayed diagnosis among human immunodeficiency virus-infected pulmonary tuberculosis suspects in a rural HIV clinic, South Africa. Tuberc Res Treat. 2012;2012.

21. Ríos-Hincapié CY, Rojas M, López M, Porras A, Luque R, Pelissari DM, et al. Delays in HIV and TB diagnosis and treatment initiation in co-infected patients in Colombia. Int J STD AIDS. 2020;31(5):410-9.

22. Coimbra I, Maruza M, Militão-Albuquerque MdFP, Moura LV, Diniz GTN, Miranda-Filho DdB, et al. Associated factors for treatment delay in pulmonary tuberculosis in HIV-infected individuals: a nested case-control study. BMC Infect Dis. 2012;12:208.

23. Nogueira BMF, Rolla VC, Akrami KM, Kiene SM. Factors associated with tuberculosis treatment delay in patients co-infected with HIV in a high prevalence area in Brazil. PLOS ONE. 2018;13(4):e0195409.

24. van der Werf MJ, Chechulin Y, Yegorova OB, Marcinuk T, Stopolyanskiy A, Voloschuk V, et al. Health care seeking behaviour for tuberculosis symptoms in Kiev City, Ukraine. Int J Tuberc Lung Dis. 2006;10(4):390-5.

25. Belkina TV, Khojiev DS, Tillyashaykhov MN, Tigay ZN, Kudenov MU, Tebbens JD, et al. Delay in the diagnosis and treatment of pulmonary tuberculosis in Uzbekistan: a cross-sectional study. BMC Infect Dis. 2014;25(14):624.

26. Rabin AS, Kuchukhidze G, Sanikidze E, Kempker RR, Blumberg HM. Prescribed and self-medication use increase delays in diagnosis of tuberculosis in the country of Georgia. Int J Tuberc Lung Dis. 2013;17(2):214-20.

27. Whitehorn J, Ayles H, Godfrey-Faussett P. Extra-pulmonary and smearnegative forms of tuberculosis are associated with treatment delay and hospitalisation. Int J Tuberc Lung Dis. 2010;14(6):741-4.

28. Hudson CP, Wood R, Maartens G. Diagnosing HIV-associated tuberculosis: reducing costs and diagnostic delay. Int J Tuberc Lung Dis. 2000;4(3):240-5.

29. Ji Y-J, Liang P-P, Shen J-Y, Sun J-J, Yang J-Y, Chen J, et al. Risk factors affecting the mortality of HIV-infected patients with pulmonary tuberculosis in the CART era: a retrospective cohort study in China. Infect Dis Poverty. 2018;7(1):25.

30. Delay in seeking care for tuberculosis symptoms among adults newly diagnosed with HIV in rural Malawi. https://pubmed.ncbi.nlm.nih.gov/ 29471905/. Accessed 1 Feb 2021.

31. HIV care and treatment factors associated with improved survival during TB treatment in Thailand: an observational study | BMC Infectious Diseases | Full Text. https://doi.org/10.1186/1471-2334-9-42. Accessed 2 Feb 2021. 
32. Bentzon AK, Panteleev A, Mitsura V, Borodulina E, Skrahina A, Denisova E, et al. Healthcare delivery for HIV-positive people with tuberculosis in Europe. HIV Med. 2021;22:283-93.

33. Herce ME, Morse J, Luhanga D, Harris J, Smith HJ, Besa S, et al. Integrating HIV care and treatment into tuberculosis clinics in Lusaka, Zambia: results from a before-after quasi-experimental study. BMC Infect Dis. 2018;18(1):536

34. Owiti P, Zachariah R, Bissell K, Kumar AMV, Diero L, Carter EJ, et al. Integrating tuberculosis and HIV services in rural Kenya: uptake and outcomes. Public Health Action. 2015;5(1):36-44.

35. Ngabonziza J-CS, Habimana YM, Decroo T, Migambi P, Dushime A, Mazarati JB, et al. Reduction of diagnostic and treatment delays reduces rifampicin-resistant tuberculosis mortality in Rwanda. Int J Tuberc Lung Dis. 2020;24(3):329-39.

36. Bulterys MA, Wagner B, Redard-Jacot M, Suresh A, Pollock NR, Moreau $E$, et al. Point-of-care urine LAM tests for tuberculosis diagnosis: a status update. J Clin Med. 2019;9(1):111.
37. WHO | Latent TB Infection: updated and consolidated guidelines for programmatic management. WHO. World Health Organization. http:// www.who.int/tb/publications/2018/latent-tuberculosis-infection/en/. Accessed 29 May 2021.

38. Kempker RR, Chkhartishvili N, Kinkladze I, Schechter MC, Harrington K, Rukhadze $\mathrm{N}$, et al. High yield of active tuberculosis case finding among HIV-infected patients using Xpert MTB/RIF testing. Open Forum Infect Dis. 2019;6(6):ofz233.

39. WHO consolidated guidelines on tuberculosis Module 2: screening-systematic screening for tuberculosis disease. https://www.who.int/publi cations/i/item/9789240022676. Accessed 8 Apr 2021

\section{Publisher's Note}

Springer Nature remains neutral with regard to jurisdictional claims in published maps and institutional affiliations.
Ready to submit your research? Choose BMC and benefit from:

- fast, convenient online submission

- thorough peer review by experienced researchers in your field

- rapid publication on acceptance

- support for research data, including large and complex data types

- gold Open Access which fosters wider collaboration and increased citations

- maximum visibility for your research: over 100M website views per year

At $\mathrm{BMC}$, research is always in progress.

Learn more biomedcentral.com/submissions 